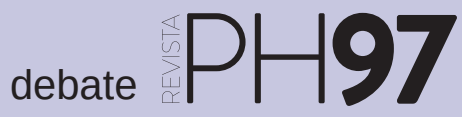

a debate El papel del patrimonio en las nuevas políticas para la cultura, la ciudad y el territorio:

las agendas urbanas como marco de oportunidad

| coordinan Blanca del Espino Hidalgo, Rafael Merinero Rodríguez

\title{
Elementos patrimoniales en la agenda urbana como antecedentes al reto de la sostenibilidad energética
}

\author{
María-José Prados Velasco | Dpto. de Geografía Humana, Universidad de Sevilla \\ URL de la contribución <http://www.iaph.es/revistaph/index.php/revistaph/article/view/4418>
}

La agenda urbana afronta el reto global de alcanzar la sostenibilidad en el desarrollo urbano a partir de la implementación de políticas. Sin rango normativo, la fortaleza de este documento parece encontrarse en la participación ciudadana entendida como la manifestación plural y organizada de demandas colectivas dirigidas a la mejora de la calidad y la convivencia en el hábitat urbano. Y también, pero no menos trascendente, en su adaptabilidad a las exigencias de quienes residen en diferentes sistemas de asentamientos en lo que se ha venido a considerar un "menú a la carta" (Agenda Urbana Española, 2019). La propia denominación de agenda urbana puede, a simple vista, repeler su adaptación en las áreas rurales porque su abordaje resulte parcial y sesgado.

En lo que al documento aprobado para la Agenda Urbana de Andalucía se refiere, la inclusión de los asentamientos rurales enfatiza en exceso en el desequilibrio demográfico y el despoblamiento rural (Agenda Urbana de Andalucía 2030, s.f.). La estructura territorial y la dimensión económica inciden en este problema, lo que evidentemente restaría capacidad de actuación a los municipios rurales. Esta imagen recurrente, que incide en una situación que siendo cierta no es exclusiva de estos ámbitos, enmascara la resiliencia de una buena parte de los ámbitos rurales andaluces. Tanto por su capacidad de emprendimiento, la atracción de población con formación o una oferta residencial de mayor calidad en lo que al entorno paisajístico se refiere, el medio rural ofrece hoy en día un potencial enorme gracias a los dinamismos promovidos por la sociedad civil. A lo que se suman los esfuerzos de los Grupos de Desarrollo Rural para la creación de redes supramunicipales en favor del emprendimiento y la fortaleza territorial de los municipios rurales. Ello no lleva a significar el protagonismo de los municipios rurales en las agendas urbanas, más bien

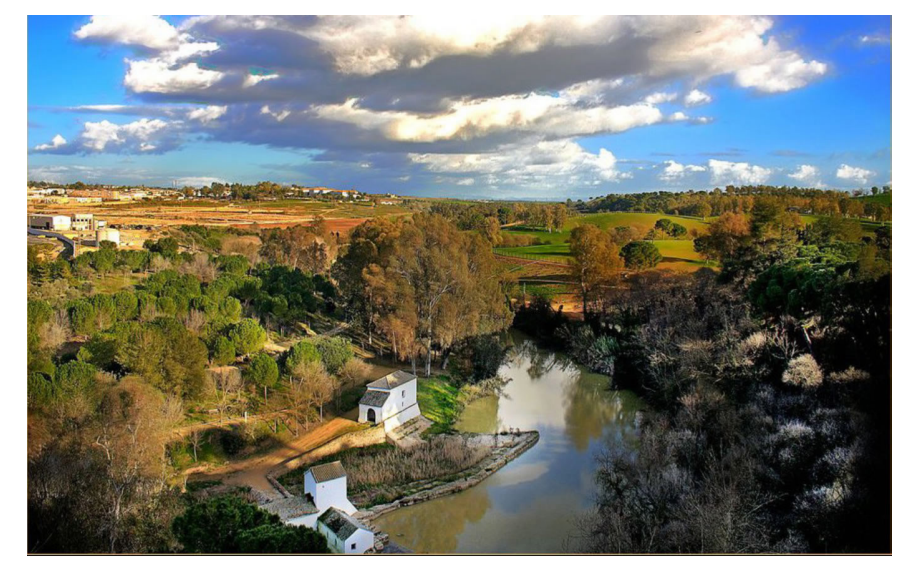

Molino de Benarosa, Alcalá de Guadiara

debe servir para dotarles de un protagonismo correcto y más ajustado a su realidad territorial. El enfoque de esta reflexión sobre el patrimonio como oportunidad en el marco de las agendas urbanas es plenamente acertado porque muchos de los procesos de dinamización y activismo rural en Andalucía están basados en la identificación, reconocimiento y puesta en valor de sus elementos. Los ejemplos son múltiples, pero quisiera centrarme en aquellos relacionados con paisajes culturales resultado de la producción de energía, intentado una lectura contemporánea de los elementos patrimoniales en el marco de las acciones a favor del tránsito hacia una economía baja en carbono.

La actividad minera es característica de muchos de los municipios enfrentados con problemas de despoblamiento resultado del decaimiento de la actividad, de una especialización excesiva o de las limitaciones inherentes a la contaminación del suelo. Pero también ha construido un capital social con formación, conciencia social y capacidad de acción. El Colectivo Proyecto Arrayanes trabaja desde 1991 a favor del patrimonio minero en 
a debate El papel del patrimonio en las nuevas políticas para la cultura, la ciudad y el territorio: las agendas urbanas como marco de oportunidad

| coordinan Blanca del Espino Hidalgo, Rafael Merinero Rodríguez

Linares-La Carolina en una apuesta conjunta a favor de la investigación y la acción dirigida a la protección, conservación, recuperación y puesta en valor del patrimonio minero industrial (https://www.proyectoarrayanes. org), como queda constatado en el Catálogo de emplazamientos mineros (http://www.proyectoarrayanes.org/ catalogo.php).

La Fundación Rio Tinto, por su parte, trabaja en esa dirección aunque combinada con una orientación cultural, turística y recreativa bien conocida (http://fundacionriotinto.es). Entre los fines de la Fundación, se menciona expresamente la cohesión social por medio de la colaboración en proyectos y estrategias de desarrollo regional y la mejora de las condiciones de vida de la población, aspectos que entran de lleno en el enfoque de la agenda urbana.

Con otros esquemas de organización y fines, pero bajo el principio de puesta en valor del patrimonio minero, mencionar además, sin ánimo de pretender ser exhaustiva, a Eiffel Lab por sus trabajos sobre las Minas de Sierra Morena (http://www.minasdesierramorena.es) o la Asociación AUFI en Los Pedroches (https://fabricareinvestigar.wordpress.com). Los ingenios y molinos hidráulicos son otro ejemplo para la puesta en valor de elementos patrimoniales en áreas rurales, como también los molinos eólicos aunque es cierto que con menor representación territorial. En los dos casos no se ha logrado sin embargo un activismo de la sociedad rural comparable al del patrimonio minero. En su lugar han sido las administraciones locales y regional quienes han asumido la identificación, defensa y puesta en valor patrimonial, en muchos casos como parte del proceso de catalogación. El caso de los ingenios y molinos hidráulicos adquiere un significado especial por cuanto están ligados al sistema hidrológico como parte de los elementos estructurales del territorio andaluz. Su lectura ofrece múltiples facetas como patrimonio territorial y testigos de paisajes culturales desaparecidos; para la llamada de atención sobre la regulación de los caudales hídricos; la contaminación de las aguas; el acceso a las orillas fluviales; o la conectividad territorial por mencio- nar sólo algunos ejemplos. Aunque quizás el más sustancial ahora es su representación como sistemas de generación de energía a partir de recursos renovables.

El debate de la agenda urbana ha de ser plural, equitativo, integrador y con visión de futuro. Hasta ahora se ha insistido en los mecanismos de participación, pero estos no serán plenamente útiles si quedan anclados en cuestiones importantes -movilidad, desigualdad, el acceso a la cultura...- dejando de lado la oportunidad de integrar otras de gran trascendencia como es el comportamiento de la población ante la energía. La lucha contra el calentamiento global no compete únicamente los acuerdos internacionales y de la política energética sino que ha de integrar acciones cotidianas a favor de una sociedad cada vez menos dependiente de los combustibles fósiles. Los elementos del patrimonio rural para la producción de energía establecen un nexo entre formas antiguas y nuevas de aprovechamiento de recursos renovables. Una mirada hacia atrás en clave rural que resulta plenamente contemporánea. Una forma de aprovechar los elementos patrimoniales a favor de la identidad territorial, el acceso a la técnica y la cultura, o el ocio y el deporte en el medio natural que otorga un papel protagonista. Es responsabilidad de las agendas urbanas en los municipios rurales centrar el debate en oportunidades locales singulares más que trasladar las de las ciudades. Un planteamiento resituado capaz de integrar a la sociedad civil del medio rural que haga posible conectar municipios con metas compartidas. 